\title{
The Wireless Network Optimization of Power Amplification via User Volume in the Microcell Terrain
}

\author{
Guo Shengnan $^{1}$, Jiang Xueqin ${ }^{2 *}$, Zhang Kesheng ${ }^{3}$ \\ ${ }^{1}$ School of Big data,Guizhou Institute of Technology \\ Guiyang China \\ [e-mail: 504349286@qq.com] \\ ${ }^{2}$ School of Electrical and Information EngineeringSchool of Engineering, Guizhou Institute of Technology \\ Guiyang China \\ [e-mail: jiaoyanshi710@163.com] \\ ${ }^{3}$ School of Electrical and Information EngineeringSchool of Engineering, Guizhou Institute of Technology \\ Guiyang China \\ [e-mail: zkslc3000@163.com] \\ Corresponding Author: Jiang Xueqin
}

Received October 26, 2017; revised December 29, 2017; accepted January 30, 2018;

published June 30, 2018

\begin{abstract}
The microcell terrain is the most common wireless network terrain in our life. In order to solve wireless network optimization of weak coverage in the microcell terrain, improve call quality and reduce the cost of the premise, power amplifiers in base stations should be adjusted according to user volume. In this paper, characteristics of microcell topography are obtained after analysis. According to the topography characteristics of different microcells, changes in the number of users at different times have been estimated, meanwhile, the number of scatter users are also obtained by monitoring the PCCPCH RSCP and other parameters. Then B-Spline interpolation method has been applied to scatter users to obtain the continuous relationship between the number of users and time. On this basis, power amplification can be chosen according to changes in the number of users. The methods adopted by this paper are also applied in the engineering practice, sampling and interpolation are used to obtain the number of users at all times, so that the power amplification can be adjusted by the number of users in a microcell. Such a method is able to optimize wireless network and achieve a goal of expanding the area of base stations, reduce call drop rate and increase capacity.
\end{abstract}

Keywords: Microcell terrain; wireless network optimization; B spline interpolation; PCCPCH RSCP , power amplification 


\section{Introduction}

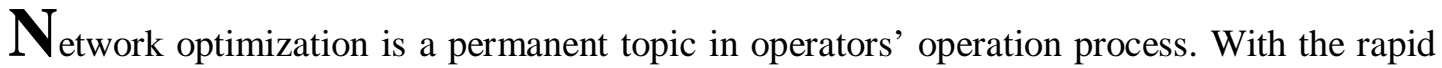
development of mobile communication industry, wireless communication almost can be used at anytime and anywhere in our daily life and work. Therefore, network optimization is the key emphasis for operators. Wireless network optimization is contributed to achieving goals of improving operation efficiency and service quality, reducing costs, increasing capacity, and enhancing stability and durability. However, it is hard for the existing wireless infrastructures in China to meet the high-rate and high-level requirements of modern social users, because preliminary design of base stations is based on theoretical value. However, there is no unified planning as constructing the network, so that service quality will be affected by increasing users and changing architectural structure. Generally speaking, operators often conduct network optimization via power amplification, but improper power amplification will waste wireless resources or weaken business quality.[1]

It's has also been one of key researches at home and abroad on how to improve the efficiency of power amplifier without wasting resources, related researches also include to optimize the wireless network with power control method, that is to say power control can suppress the inter-cell interference while making up the path loss and shadow fading, so as to guarantee the signal to reach the target signal-to-noise ratio of uplink transmission. For example, in case [2], a tractable model was introduced to analyze the energy efficiency of uplink power control in multi-tier HetNet systems. However, most researches on the power control mainly focus on the improvement of details and algorithms. Research on the application of domestic wireless network planning in engineering practice can be known in reference [3]. In reference [3], it's introduced that the uplink power control makes different UE to achieve an equal Power Spectral Density of eNodeB as the MCS keeps the same. When having the wireless network optimization for engineering practices, as the degree of construction, coverage and optimization in various places are not the same, $2 \mathrm{~g} / 3 \mathrm{~g} / 4 \mathrm{~g}$ networks will be interoperated to fully guarantee the user experience [4], therefore, the optimization and improvement of LTE is mainly discussed in this paper. Related research results of power amplification and control are also involved in this paper, more attention is also paid to the application of engineering practice. Finally, it's proved through the simulation and engineering practice that the wireless optimization in the microcell topography proposed in this paper is of practical significance.

\section{Wireless Communication Problems in the Microcell Terrain}

The microcell terrain is the common type in modern wireless network optimization and has practical significance on its analysis

\subsection{Microcell Terrain}

The microcell terrain refers to the community with the radius of one kilometer. Relative to the larger wireless network area, the community covered by wireless signals is relatively small, such as a residence community with 1000 residents, small and medium-sized hotels and small and medium-sized squares, etc.

The microcell terrain has the following features: Firstly, wireless network environment is small and handover is not frequent. Secondly, time quantum for users who use wireless network is unfixed and it is relatively scattered. Thirdly, with the large flotation of number of 
users, it is easy to cause place extreme utilization. In other words, usage rate will reach the peak or valley at certain time quantum or certain time point. Fourthly, community buildings are relatively dense or fixed. Because early wireless communication facilities have been completed, it is not suitable to increase equipment to optimize it.

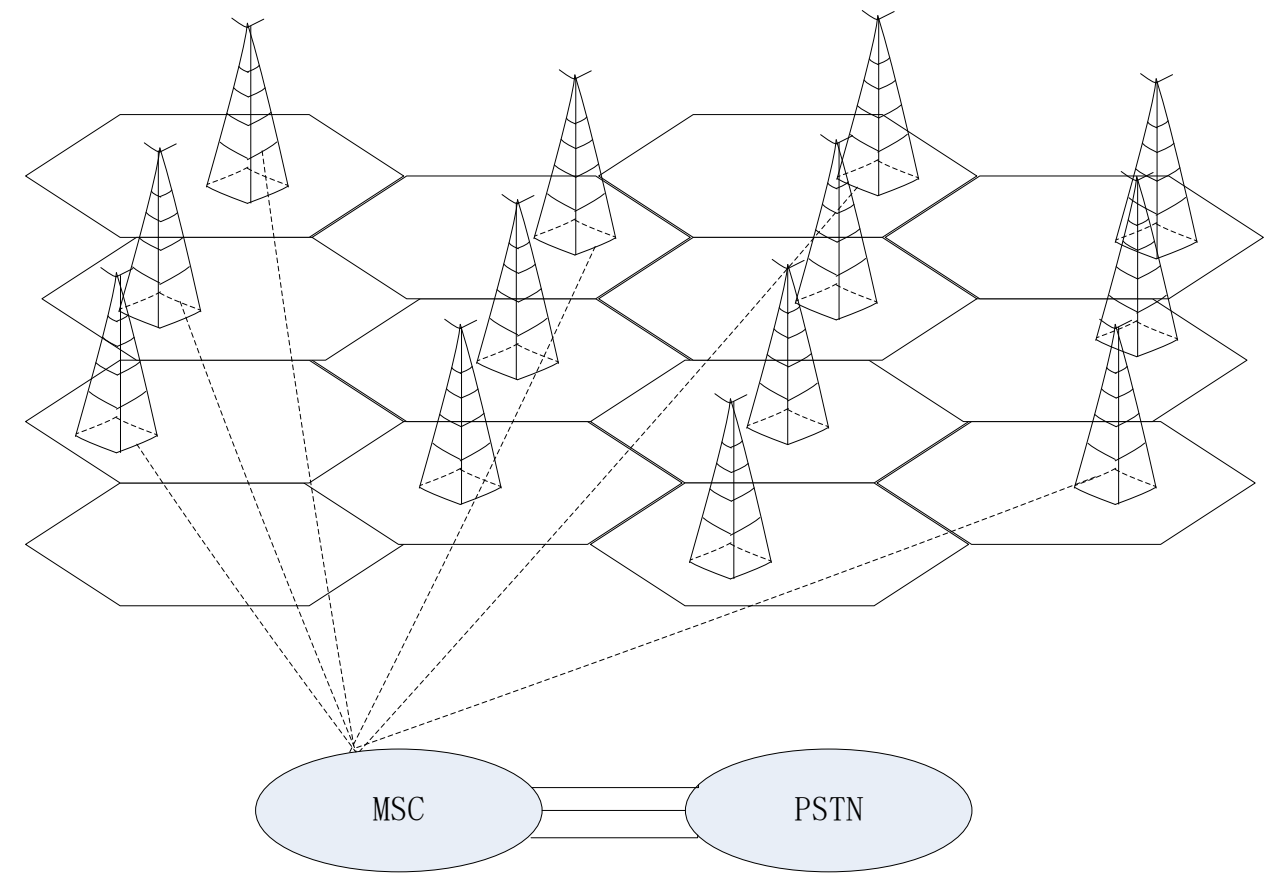

Fig. 1. microcell terrain

Wireless communication network problems in occurred in the microcell terrain generally can be divided into several types, such as call drop, call failure, communication outage and call delay, and so on. In addition, causes of these problems should be classified into equipment failure in base stations, environmental noise and signal coverage. In the paper, the problem to be discussed and solved in this paper is the coverage issue.

\subsection{Common Solution for Weak Coverage}

Poor signals or call drop and unavailable signals in the microcell terrain are often attributed to the coverage issue, which gets involved in excessive coverage, weak coverage and chaotic coverage or something else. In the paper, wireless network optimization is mainly attributed to weak coverage. In general, operators not only should conduct technical adjustment, but also should modify surroundings in design, for the sake of solving a problem of weak coverage. In the engineering practice, workers have done plenty of work in design. Limited by the paper length, the author won't give unnecessary details in the paper.

There are three methods modifying the weak coverage:

(1) to increase base stations; (2) to increase repeaters and expand signals of original base stations under the precondition without increasing base stations; (3) to enhance emission power of original base stations under the precondition without increasing base stations. In the paper, the third mode is selected to optimize wireless network. In other words, base stations' emission power is enhanced.[5]

It can be observed from the following Fig. 2 that with the increase of emission power in base stations, coverage range of wireless signals will be increased. When emission power is $\mathrm{P} 1$, the 
radius of coverage range is R1. Correspondingly, radius for P2 is R2. As P2>P1, there is $\mathrm{R} 2>\mathrm{R} 1$. However, it is worth noting that island effect should be avoided as enhancing base stations' emission power to increase the coverage area. That is to say, when a mobile phone is far away from a base station and it is still kept in the island area of this base station, the community around the island is not the neighbor community of the above-mentioned one. Therefore, once the mobile station is moved out of the island, the island will take place call drop.

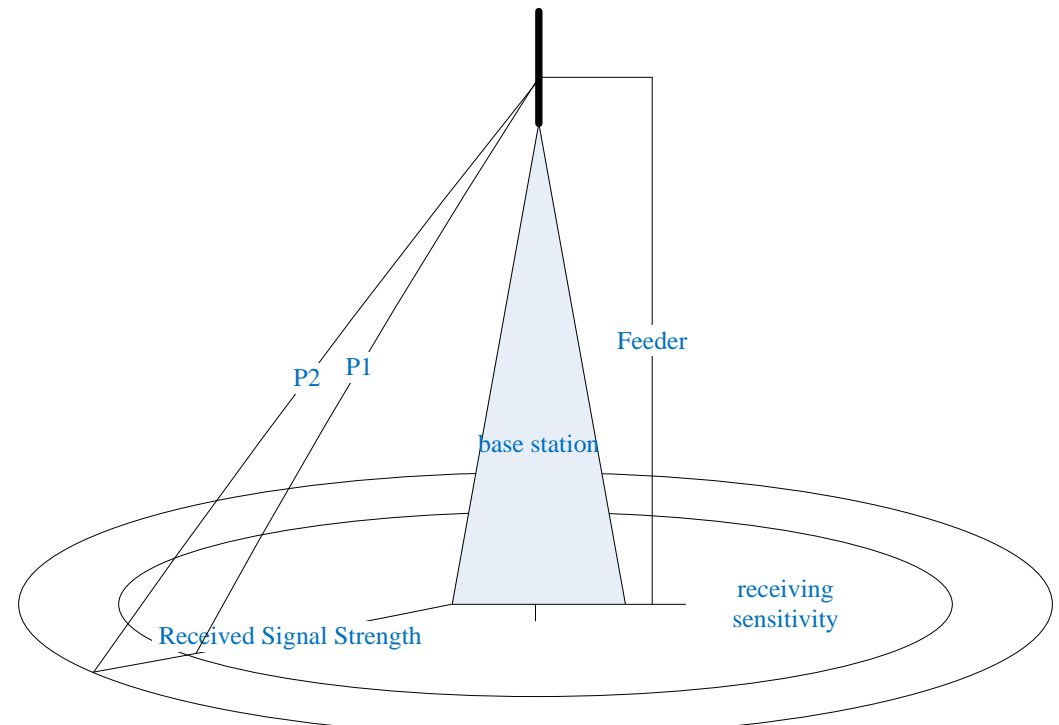

Fig. 2. Base Station Power and Signal Coverage

\section{Amplification of Base Stations' Emission Power According to User Volume}

In addition to weak coverage, other wireless communication problems also can be solved by improving base stations' emission power. Enhancement of emission power can improve upstream reception level, reduce call drop rate, decrease output power of mobile phones, and reduce disturbance. Within limits, input power and output power are presented in linearity before saturation. However, if emission power is blindly improved, output power won't be increased in the saturation condition. On the contrary, output power even will be reduced. For reduce this effect, distribution pressure of user volume is confirmed in the microcell terrain to how to amplifying power.

\subsection{Amplification of Base Stations' Emission Power}

The largest influence factor of radio waves in propagation paths is communication environment (work frequency $\mathrm{f}$ and propagation distance $\mathrm{s}$ ). When $\mathrm{f}$ or $\mathrm{s}$ is doubled, propagation loss is increased by $6 \mathrm{db}$. Particularly, the TD-LTE operator is frequently used in China. The carrier frequency is about $2 \mathrm{GHz}$. High-frequency radio wave has the large radio wave attenuation. The effective coverage radius of base stations will be small. Therefore, amplification of emission power is the simplest method to increase wireless coverage range and intensify wireless signal strength under the precondition without considering other practical conditions. 
In order to make the best of resources and achieve high-efficient utilization, linear power amplifiers should be applied in emission of base stations. However, general power amplifiers have their own fixed regulative range. If the range is exceeded, it will take place supersaturation, as shown in Fig 3. The increase of input power won't affect output power. Moreover, when power amplifiers are kept in the non-linear areas, modulating signals changed by envelope will generate intermodulation distortion after passing through non-linear RF power amplifiers, resulting in serious intersymbol interference and adjacent channel disturbance.[6]

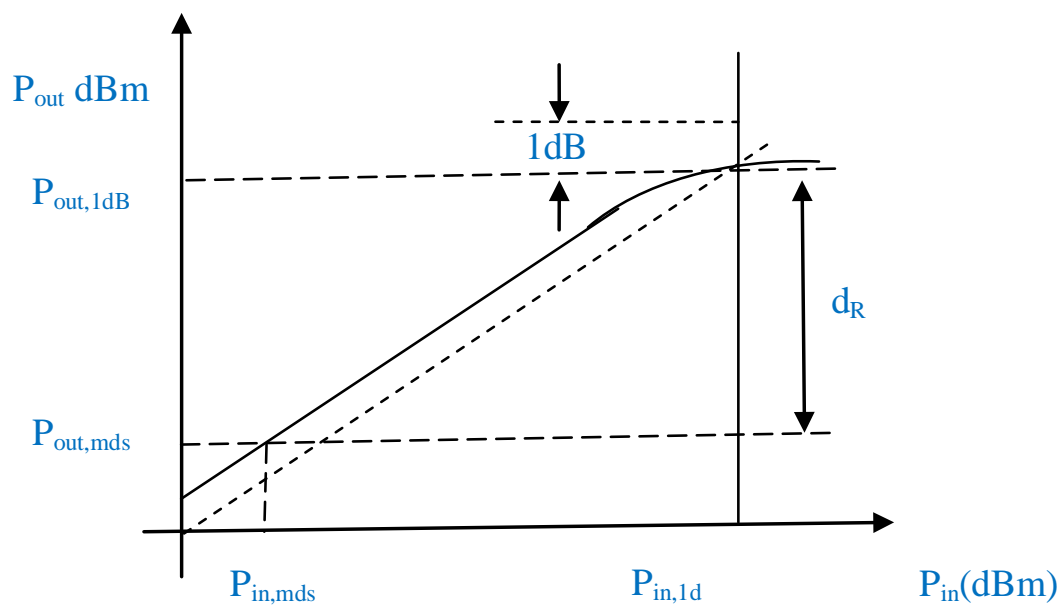

Fig. 3. Input-output Power Function Relationship of Power Amplifiers

\subsection{User Volume and Time Function Obtained by B Spline Interpolation}

With the flourishing development of big data in modern times and attention of various industries on collecting storage data information, it is possible to analyze actual applications of data and cloud computing. By combining with cloud computing and information treatment, data in the microcell terrain are applied in the paper to obtain three categories of typical microcell terrains: the residence community;the hotel; the square. Next, user volume, PCCPCH RSCP and time in three categories of microcell terrains are collected. Simulation is used to calculate features of several typical microcell terrains and user volume with time relationship.

(1) User Volume in Three Categories of Microcell Terrains

First of all, use volume of existing base station equipment in three typical microcell terrains is collected and these users collected can be divided into the bigges online user volume, activated user volume, inactivated user volume and the biggest concurrent user volume. Next, parameter data of user equipment(UE) are collected, including pccpch-rscp. Meanwhile, judgment conditions $-95 \mathrm{dbm}<$ pccpch-rscp $<-45 \mathrm{db}$ (PCCPCH C/I $>-3 \mathrm{~dB}$, UE TXPOWER $<24 \mathrm{dBm}$ ) are provided. If it is kept in the value range of judgment conditions, it shows that the user is using wireless communication, so as to record user volume at certain time.[7]

Operator data before network optimization are applied. Data in three communities that greatly conform to features of the microcell terrain are analyzed. 
(2) Normalization of User Volume

For user volume collected, it must be normalized before data analysis. Normalization is a method for dimensionless method of data and the min-max normalization of above-mentioned data. 500 is set up as the max user volume $\mathrm{N}_{\max }$ in three terrains. Similarly, $\mathrm{N}_{\min }=0$ is set up. User volume $\mathrm{N}_{\mathrm{r}}$ in the community, square and hotel is mapped in $\mathrm{N}_{\text {nor }}$ of the interval $[0,500]$ via the min-max normalization, obtaining the formulas (1), (2) and Table 1(ignore decimals).

$$
\begin{array}{r}
\mathrm{N}_{\max }=500 \quad \mathrm{~N}_{\min }=0 \\
\mathrm{~N}_{\text {nor }}=\left(\mathrm{N}_{\mathrm{r}}-\mathrm{N}_{\min }\right) /\left(\mathrm{N}_{\text {max }} \mathrm{N}_{\min }\right)
\end{array}
$$

Table 1. Sampling Points of User Volume in a Day(24h)

\begin{tabular}{|c||c|c|c|c|c|c|c|c|c|}
\hline Tites & 0 & 4 & 8 & 12 & 16 & 18 & 20 & 22 & 24 \\
\hline The community & 51 & 5 & 302 & 112 & 111 & 302 & 412 & 455 & 203 \\
\hline The square & 22 & 0 & 312 & 104 & 161 & 200 & 456 & 398 & 18 \\
\hline The hotel & 153 & 52 & 256 & 368 & 210 & 250 & 401 & 444 & 205 \\
\hline
\end{tabular}

(3) Simulation of B Spline Interpolation

Sampling period of data in Table $\mathbf{1}$ is / $\mathrm{d}(24 \mathrm{~h})$; user volume obtained is the discrete data, which can't embody the correspondence with other time. Three-order B spline interpolation is applied to obtain the relationship between user volume and periodic continuity.

$\mathrm{B}$ spline curves are composed of linear combination of primary function and control vertex P-order B spline primary function is written into $\mathrm{Ni}, \mathrm{p}(\mathrm{t})$; and node vector is $\mathrm{r}(\mathrm{t})$, and there are formulas (3), (4) and (5).

$$
\begin{gathered}
r(t)=\sum_{\mathrm{t}=0}^{n} N_{i, k+1}(t) P_{i}, t \in\left[t_{k}, t_{n+1}\right] \\
N_{i, 1}(t)=\left\{\begin{array}{l}
1, t_{i} \leq t \leq t_{i+1} \\
0, \quad \text { other }
\end{array}\right. \\
N_{i, p}(t)=\frac{t-t_{i}}{t_{i+p-1}-t_{i}} \cdot N_{i, p-1(t)}+\frac{t_{i+p}-t}{t_{i+p}-t_{i+1}} \cdot N_{i+1, p-1}(t), i=0,1, \ldots, n, p>1
\end{gathered}
$$

Accumulative chord length method is used in B spline curve interpolation point. Point Qj is inserted in the interpolation point parameter. There are formulas (6) and (7), obtaining the corresponding curve ${ }^{5}$.

$$
\begin{gathered}
\tau_{0}=0, \tau_{i}=\tau_{i-1}+\frac{\left|Q_{i}-Q_{i-1}\right|}{d} \text {, and } d=\sum_{i=0}^{n-1}\left|Q_{i}-Q_{i+1}\right| \\
Q_{j}=r\left(\tau_{j}\right)=\sum_{\mathrm{t}=0}^{n} N_{i, k+1}\left(\tau_{j}\right) P_{i}, j=0,1, \ldots, n
\end{gathered}
$$

Then, simulation is conducted by Matlab. The simulation results of three microcell terrains are shown in Fig 4, 5 and 6: 


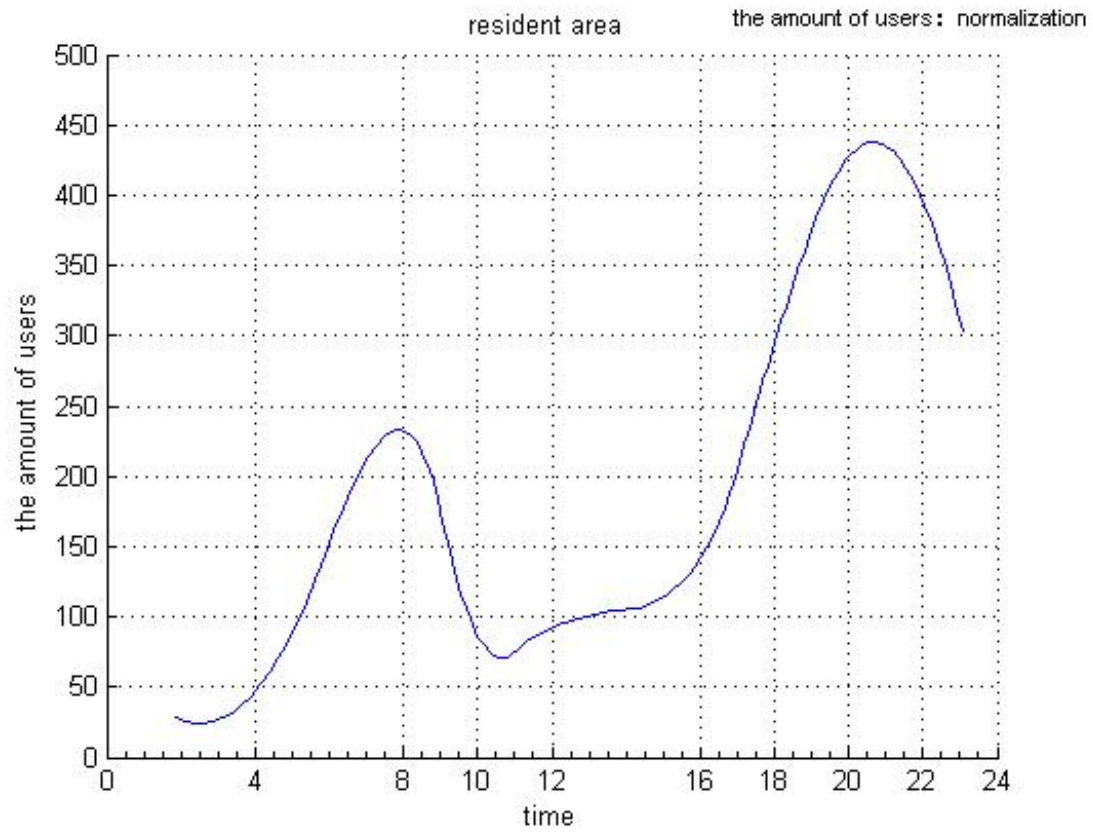

Fig. 4. the amount of users in resident area

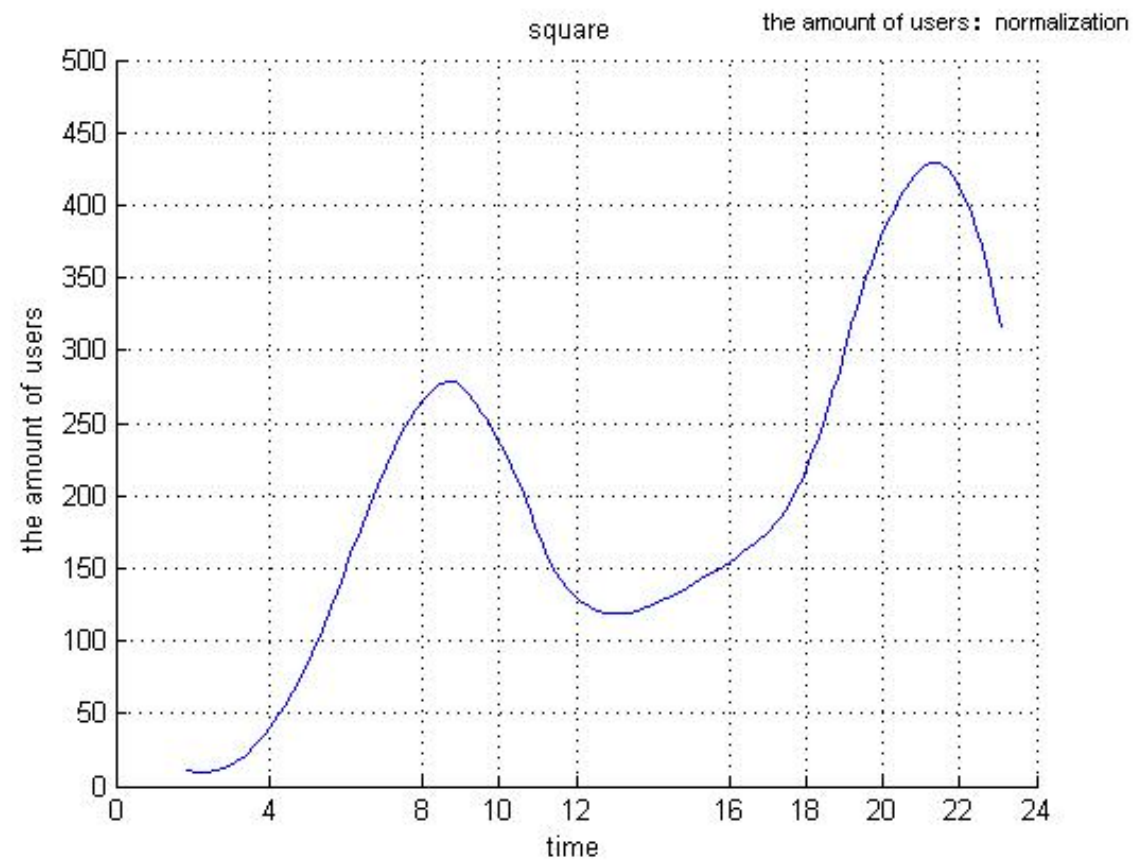

Fig. 5. the amount of users in square 


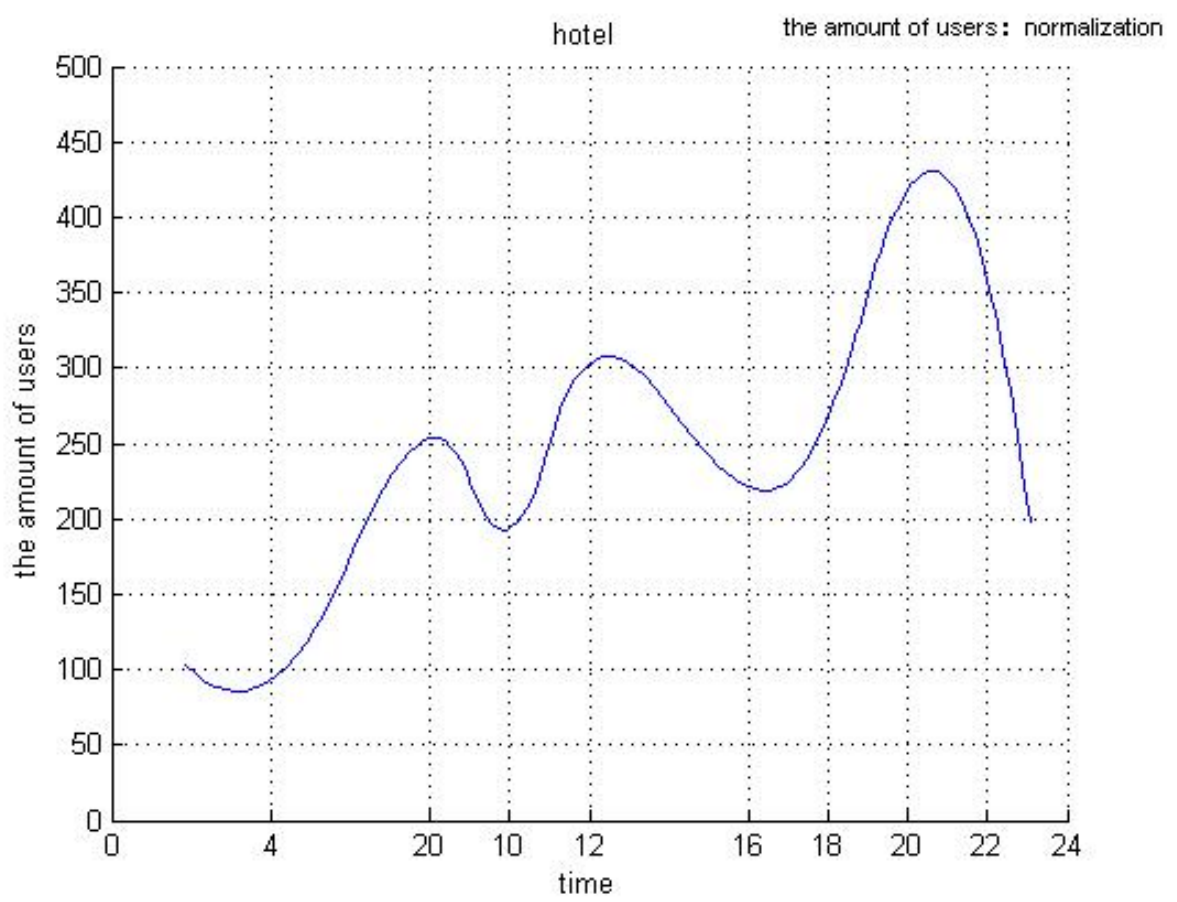

Fig. 6. the amount of users in hotel

\subsection{Changing Discipline of User Volume in Three Microcell Terrains}

Changing discipline of user volume in three microcell terrains is shown in Fig 4, 5 and $\mathbf{6}$ :

A. At 8 o'clock and 20 o'clock, there are more users and less work time.

B. There is continuous peak on weekends and holidays. There are more users at 20 o'clock on workdays.

C. There are more users at 8 o'clock, 12 o'clock and 20 o'clock. User volume is distributed unevenly.

According to changing situation of user volume, user volume is divided into four types: a few users, common users, more users and lots of users. The corresponding power amplification range of user volume changes can be classified into four types: $0-\mathrm{P}_{\mathrm{L}}, \mathrm{P}_{\mathrm{L}}-\mathrm{P}_{\mathrm{M}}, \mathrm{P}_{\mathrm{M}}-\mathrm{P}_{\mathrm{H}}$ and $\mathrm{P}_{\mathrm{H}}-\mathrm{P}_{\mathrm{SH}}$. $\mathrm{P}_{\mathrm{L}}, \mathrm{P}_{\mathrm{M}}, \mathrm{P}_{\mathrm{H}}$ and $\mathrm{P}_{\mathrm{SH}}$ mainly refer to PCCPCHPOWER(PCCPCH channel powers), including emission power of PCCPCH's two code channels in the community. The parameter value is between 60 and 400. Physical value is between 6 and 40. The step length is 0.1 and physical unit is $\mathrm{dBm}$. In practical application, base stations' emission power not only includes PCCPCHPOWER, but also contains others, such as Huawei single channel TDS power $=\mathrm{MAX}$ (sum of channel power on TS0 and sum of carrier power in the community)/8, and sum of TS0 power $=$ PCCPCHPOWER $* 2+$ PICHPOWER + MAXFPACHPOWER +SCCPCHPOWER*SCCPCH number of branches; Ericsson RS power $=10 * \lg$ [the largest emission power of antenna end/(RB number*12)* 1000]-PA.[8]

Meanwhile, four different power amplifiers can be selected in line with different power amplifier ranges or power amplifiers with adjustable power amplifier ranges can be selected. In the engineering practice, four different power amplifiers can be selected and switched according to different user volume. In this way, power amplifiers can be always maintained the ideal linear state, meet superposition principle, and always work in the linear amplifier 
region $\mathrm{P}_{\mathrm{in}, \mathrm{mds}}-\mathrm{P}_{\mathrm{in}, 1 \mathrm{db}}$.

In the same time, the user volume is analyzed to obtain the relation schema between user volume and time above. And the schema can be utilized to predict changing tendency of user volume in advance, so that it won't be switched frequently between different power amplifiers to affect wireless communication quality.

\section{Engineering Practice and Analysis}

The overall flow chart in the engineering practice can be obtained as follows Fig 7 :

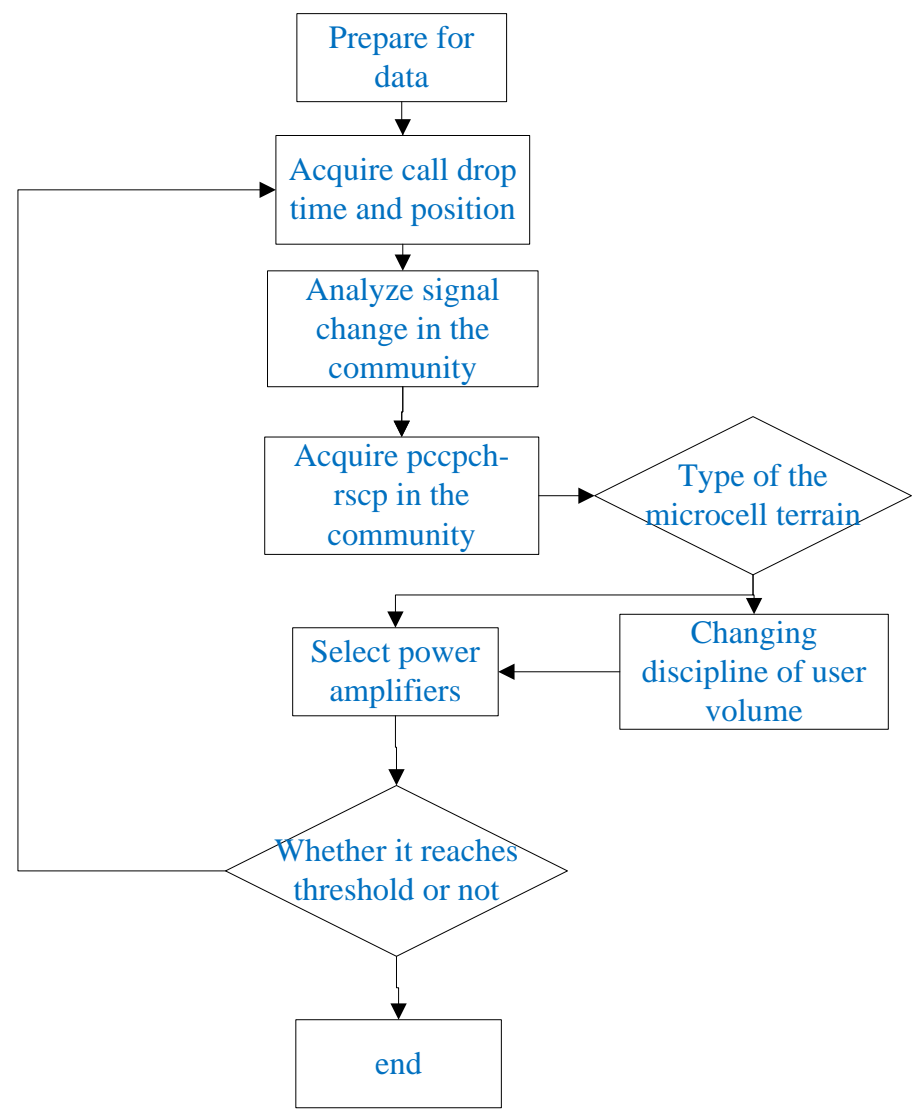

Fig. 7. Wireless Network Optimization Process

The engineering practice site is located in Xinmixin Bay Holiday Inn of Zhengzhou Branch, the east of $100 \mathrm{~m}$ from the northern intersection between Xinmi West Road and Ping'an Road. It belongs to Xinmi Branch. The hotel covers an area of $2016 \mathrm{~m}^{2}$ and has $24192 \mathrm{~m}^{2}$ of overall floorage. It is a four-star hotel(12 floors) building and now the building comes into use. As detection, it can be found that the building has more partitions. Primary partition materials include concrete and brick wall. It belongs to the hotel type in the above-mentioned three typical microcell terrains. There are more users in the morning, at noon and in the evening. User volume is distributed unevenly. According to corresponding power amplification, power control is set up. The modified detection results are shown as follows $(1 \mathrm{~F}, 5 \mathrm{~F}, 7 \mathrm{~F}, 10 \mathrm{~F}$ and $13 \mathrm{~F}$ are tested). Fig. 8 is location map of the Holiday Inn situation. 


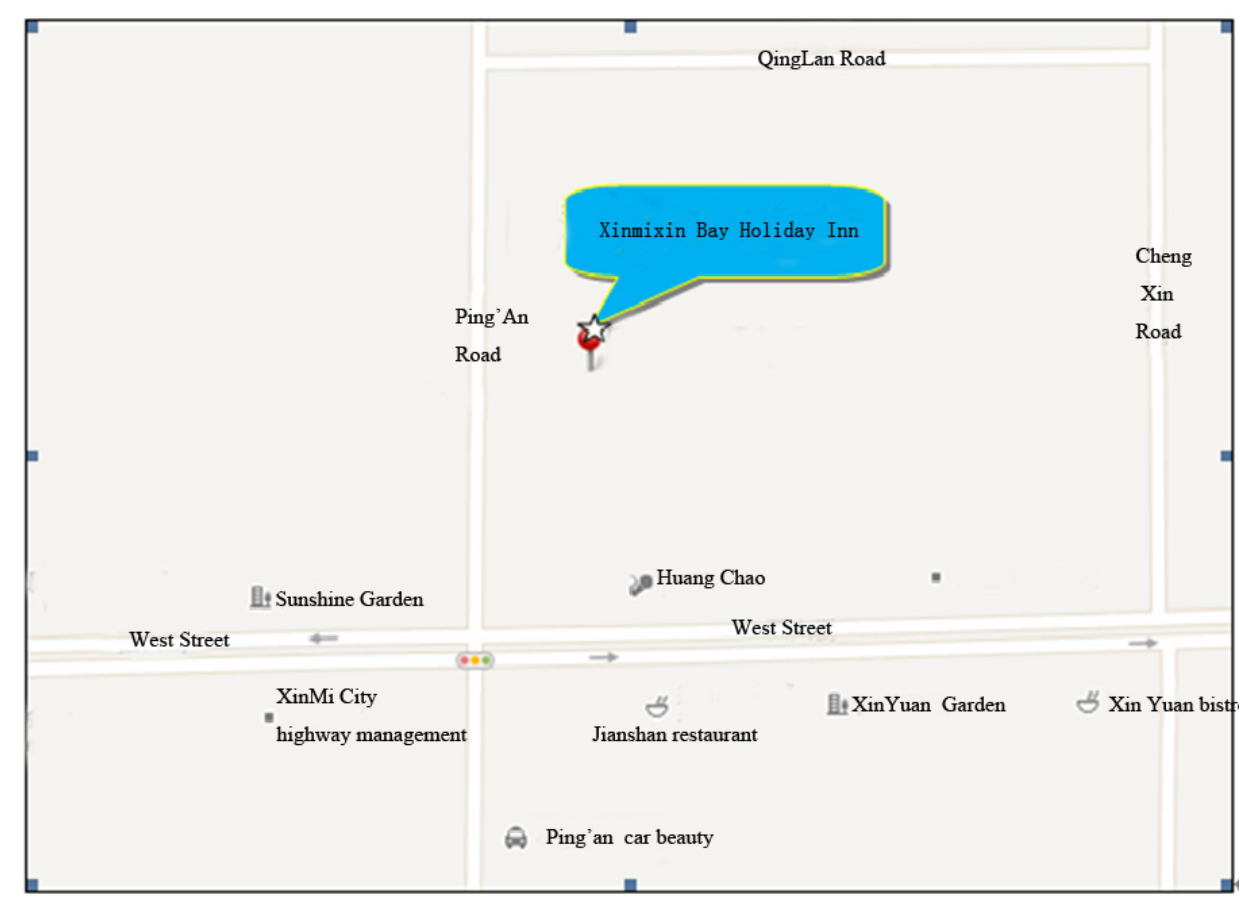

Fig. 8. Building location map

\subsection{Drive Testing (DT) Field Intensity}

From Fig 9, the strength of PCCPCH RSCP is greater than the threshold value.

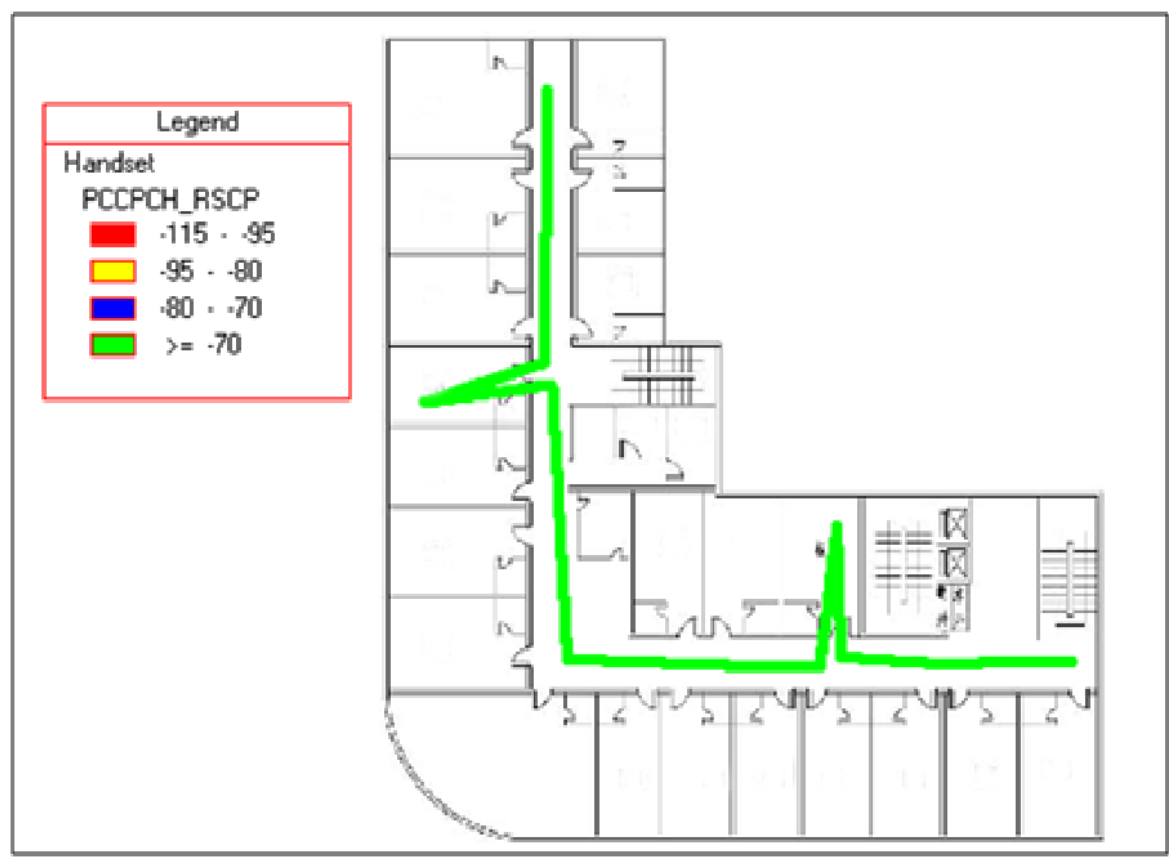

Fig. 9. PCCPCH RSCP strength distribution map 


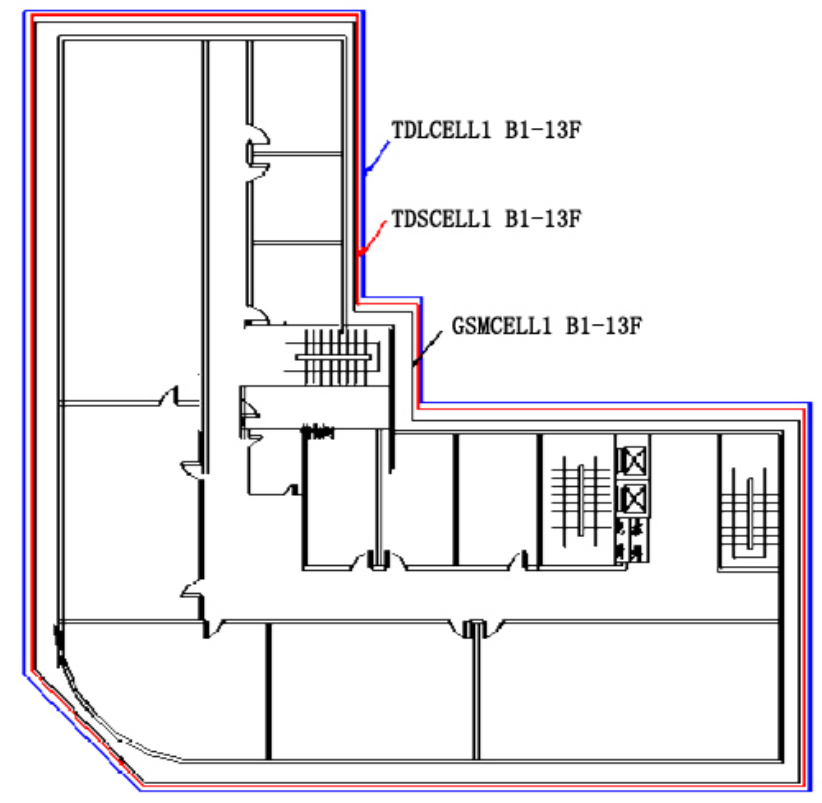

Fig. 10. GSM,TD-LTE distribution

Table 2. DT Reception Level Distribution Table

\begin{tabular}{|c|c|c|c|c|}
\hline \multicolumn{5}{|c|}{ Serving Downlink Level } \\
\hline Rxlev (dbm) & $\mathbf{2 - 7 0}$ & $\mathbf{- 7 0 - \mathbf { 8 0 }}$ & $\mathbf{- 8 0 - \mathbf { 9 5 }}$ & $\leq-\mathbf{9 5}$ \\
\hline \hline Sampling points & 320 & 0 & 0 & 0 \\
\hline Percent (\%) & 100 & 0 & 0 & 0 \\
\hline
\end{tabular}

\subsection{Communication Quality}

Table 3. Downlink Quality Table

\begin{tabular}{|c|c|c|c|c|}
\hline \multicolumn{7}{|c|}{ Downlink Quality } \\
\hline Level & $\mathbf{2 1 0}$ & $\mathbf{3 - 1 0}$ & $\mathbf{- 3 - 3}$ & $<-3$ \\
\hline \hline Sampling points & 520 & 0 & 0 & 0 \\
\hline Rate & 100 & 0 & 0 & 0 \\
\hline
\end{tabular}

Table 4. Indoor Point Test Call and Switch Statistics

\begin{tabular}{|c|c|}
\hline Event name & Time statistics \\
\hline \hline Outgoing Call Attempt & 25 \\
\hline Outgoing Call Setup & 25 \\
\hline Call Complete & 25 \\
\hline Handover Request & 5 \\
\hline Hard Handover Successfully & 5 \\
\hline
\end{tabular}




\begin{tabular}{|c|c|}
\hline Event name & Time statistics \\
\hline Call success rate & $100 \%$ \\
\hline Switch success rate & $100 \%$ \\
\hline
\end{tabular}

\subsection{CallQualityTest-CQT}

Table 5. call quality test in Xinmixin Bay Holiday

\begin{tabular}{|c|c|c|c|c|c|c|}
\hline Floors & Test points & Cell ID & $\begin{array}{c}\text { Rxlev Sub } \\
\text { (dBm) }\end{array}$ & $\begin{array}{c}\text { The first } \\
\text { neighbor }\end{array}$ & $\begin{array}{c}\text { The second } \\
\text { neighbor }\end{array}$ & $\begin{array}{c}\text { The third } \\
\text { neighbor }\end{array}$ \\
\hline \hline 1F & Corridor & 11311 & -56 & 48236 & 15340 & 15346 \\
\hline $1 \mathrm{~F}$ & Step ladder & 11311 & -53 & 15346 & 15340 & 48236 \\
\hline 1F & Corridor & 11311 & -58 & 15340 & 15346 & 48236 \\
\hline $7 \mathrm{~F}$ & Corridor & 11311 & -52 & 48236 & 15340 & 15346 \\
\hline $7 \mathrm{~F}$ & Corridor & 11311 & -57 & 15340 & 15346 & 48236 \\
\hline $7 \mathrm{~F}$ & Corridor & 11311 & -58 & 48236 & 15340 & 15346 \\
\hline $13 \mathrm{~F}$ & Corridor & 11311 & -58 & 48236 & 15340 & 15346 \\
\hline $13 \mathrm{~F}$ & Step ladder & 11311 & -54 & 48236 & 15346 & 15340 \\
\hline $13 \mathrm{~F}$ & Corridor & 11311 & -64 & 48236 & 15340 & 15346 \\
\hline
\end{tabular}

According to above charts and tables(for example the perspectives of drive testing PCCPCH-RSCP, reception level, indoor point test call and switch statistics) in 3 section, drop call rate has been reduced and quality of connection has been obviously improved as the operators are trying to reduce equipment spending, DT test reception level and other parameters reach the standard requirements. Fig. $\mathbf{1 0}$ is the overall plan of GSM/TD-s/TD-L/WLAN cell allocation. Because common site base station is the most common seen in engineering practice, namely the $2 \mathrm{G} / 3 \mathrm{G} / 4 \mathrm{G}$ systems share power, battery, air conditioning and transmission, Fig. 10 shows that several different systems can meet user requirements in the test. In the engineering practice hotel in this article, the optimization of wireless networks will be affected by the size, shape, structure, room layout, and furnishings of the building. In the process of transformation, we should try to transform and utilize the existing distribution system as far as possible, introduce the power amplifier by the way of combination. The principle of transformation is to make use of existing network resources and avoid repeating investment.

\section{Summary}

In this paper, a method of selecting power amplifiers based on the number of users and time is proposed. According to reference 3 , when the method proposed in this paper is applied in the microcell topography (the hotel), the wireless coverage will be full without missing, high connection rate and continuous connection, the voice is clear and undistorted, thus guaranteeing the network capacity meets the user's requirements for high-speed development. The result of engineering practice shows that without increasing the base stations, the 
optimized wireless network based on this method could improve the performance of base stations and reduce the coverage blind spots in the service area by amplifying power, as well as increasing the coverage quality of signal and reducing the cost of wireless network optimization. Further research will focus on combining power control to optimize, which may bring a more obvious improvement on improving the signal-noise ratio and enhancing the cell throughput.

At last, thanks to the support of Guizhou Science and Technology Fund: J No.[2014]2082 (Research on PCCPCH Coverage Optimization of Mobile TD - SCDMA Network Based on Cloud Computing Environment) and the support of the National Natural Science Foundation of China (Grant No. 61461008), the Natural Science Foundation of Guizhou Province, China (Grant No. Qian Ke He J Zi [2015]2065).

\section{References}

[1] José Ángel Fernández-Segovia, Salvador Luna-Ramírez, Matías Toril, Ana Belén Vallejo-Mora, Carlos Úbeda, "A computationally efficient method for self-planning uplink power control parameters in LTE[J]," EURASIP Journal on Wireless Communications and Networking, 2015, Vol.2015 (1), pp.1-13Article (CrossRef Link)

[2] "Energy Efficiency Evaluation of Multi-Tier Cellular Uplink Transmission Under Maximum Power Constraint," IEEE Transactions on Wireless Communications, Vol.16, No.11, pp.7092-7107, Nov 2017. Article (CrossRef Link)

[3] Wireless Network Planning and Implementation of Engineering Practice--Participant Manual[EB/OL]. Article (CrossRef Link)

[4] 2G3G4G Interoperable Neighborhood and Parameter Configuration China Mobile[EB/OL]. Article (CrossRef Link)

[5] Tan Qihong, "Discuss the applilance of repeater in mobile communication[J]," China Academic Journal Electronic Publishing House, NO.13.2013: 67-69Article (CrossRef Link)

[6] Liu Hui, "Research on Linearization Technologies for Radio Frequency Power Amplifier[D]," Xi'an: Xidian University, 2005. Article (CrossRef Link)

[7] TANG Wen-jing, MA Mei, XU Jia-pin, "Performance measurement of wireless system simulations,” China Measurement Technology, Vol 31 No 4, July,2005:63-65

Article (CrossRef Link)

[8] Power enhancement calculation method for LTE station[EB/OL]. Article (CrossRef Link) 


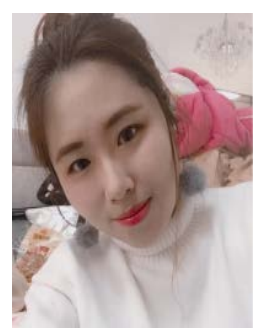

Guo Shengnan received the M.S. degree in Communication and information system from Guizhou University, Guizhou, China, 2012. Her research interests include wireless networks and communication network security.

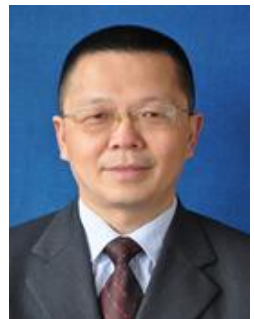

Jiang Xueqin received the M.S. degree in Communication and information system from Yunan University, Yunan, China, 2003. Now, he is aProfessor in Guizhou Institute of Technology. His research interests include propagation of electronmagnetic waves and antennas.

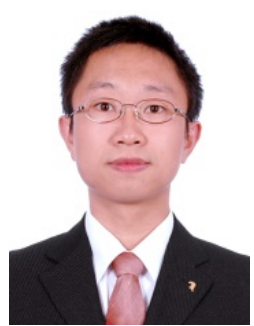

Zhang Kesheng received the Ph.D. degree in Communication and information system from Huazhong University of Science and Technology, Wuhan, China, 2013. His research interests include acoustic sensor technology and wireless networks. 